\title{
BIBECHANA
}

A Multidisciplinary Journal of Science, Technology and Mathematics ISSN 2091-0762 (Print), 2382-5340 (Online)

Journal homepage: http://nepjol.info/index.php/BIBECHANA

Publisher: Research Council of Science and Technology, Biratnagar, Nepal

\section{Fuzzy linear mathematical programming in agriculture}

\author{
M A. Lone ${ }^{1,}$ M. S. Pukhta ${ }^{*}$ S. A. Mir ${ }^{1}$ \\ Division of Agri-Statistics, Sher-e-Kashmir University of Agricultural Sciences and Technology \\ of Kashmir, India - 190025 \\ "E-mail: mspukhta_67@yahoo.co.in \\ Article history: Received 08 August, 2015; Accepted 13 September, 2015 \\ DOI: http://dx.doi.org/10.3126/bibechana.v13i0.13363
}

\section{Abstract}

In this paper we present a Fuzzy linear Mathematical programming approach for optimal allocation of land under cultivation. Fuzzy Mathematical programming approach is more realistic and flexible optimal solution for the agricultural land cultivation problem. In this study we have discussed how to deal with decision making problems that are described by Fuzzy linear programming (Flp) models and formulated with the elements of uncertainty. This form of approximation can be convenient and sufficient for making good decisions.

CRCOST: All rights reserved.

Keywords: Fuzzy linear programming; trapezoidal membership function; maximizing income; and crop combination.

\section{Introduction}

Many problems in agriculture planning, science and engineering are important from both social as well as economic point of view. There is always a need of more production to meet the increasing demands of the population. Farmers usually encountered large number of problems related to allocate the optimum number of plants in their farms in order to get the best possible result. There are number of ways of achieving high productivity is to increase the area under cultivation. The production of crops can be increased by proper utilization of resources. The most crucial factor in agriculture is planning; several operations research techniques have been used in agricultural planning. The most commonly used technique in agricultural planning is linear programming (LP). In reality, a manufacturer may start a production process with budget i.e. a minimum amount for investment. But in course of time the manufacture may have to invest a little more than the initial proposed budget in the interest of his production process. In this situation fuzzy set theory can be used to formulate the model with the help of membership functions. Again in real life situations, a linear programming model involves parameters 
whose values are not known but assigned by experts. These assigned values are not exact and the decision maker has to deal with uncertainties that are described by manufacture. We will study fuzzy linear programming (FLP) models in which the parameters are known only partially to some degree of precision. The first mathematical formulation of fuzziness was pioneered by Zadeh [1]. Orlovsky [2] made a numerous attempts to explore the ability of fuzzy set theory to become a useful tool for adequate mathematical analysis of real world problems. Several authors use different methods to solve the various types of FLP problems. Fuzzy methods have been developed in virtually all branches of decision making problems can be found in Tamiz [3], Zimmermann [4] and Ross [5]. Senthilkumar and G.Rajendran [6] solve the FLPP with fuzzy variables in parametric form. The comparisons between fuzzy numbers using ranking functions can be found in Campos and Verdegay [7] and Maleki et al [8] where crisp model is defined. In this paper a methodology to solve the Fuzzy linear programming (FLP) problem with trapezoidal membership is considered.

\section{Model formulation}

Consider the following linear programming model:

$\left.\begin{array}{r}\text { Maximize } \mathrm{z}=\mathrm{CX} \\ \text { Subject to } \mathrm{AX} \leq \mathrm{B} \\ \mathrm{X} \geq 0\end{array}\right\}$

where $\mathrm{C}=1^{\times} \mathrm{n}$ vector of components, $\mathrm{A}=\mathrm{m} \times \mathrm{n}$ matrix of coefficients, $\mathrm{B}=\mathrm{n} \times 1$ vector of all crisp parameters and $\mathrm{X}=$ is a decision variable vector.

\section{Definitions:-}

1) A fuzzy vector $x$ is a basic solution of the FLPP if it satisfies set of constraints $(A x \leq b)$.

2) A fuzzy vector $x$ is a feasible solution of the FLPP if it satisfies set of constraints $(A x \leq b)$ non-negativity condition $x \geq 0$.

3) A feasible solution of fuzzy vector $x$ that optimizes the objective function $Z=C x$ is the optimal solution to the FLPP.

4) The value of the objective function provided by the optimal solution is called an optimal value. The characteristic function

5) The characteristic function $\mu_{A}$ of crisp set $A \subseteq X$ assigns a value 0 or 1 to each member in $X$ .This function can be generalized to a function $A \sim \mu$ such that the value assigned to the element of the universal set $\mu_{A}: X \in[0,1]$ and indicates the membership grade of the element in the set. The function $\mu_{A}(x)$ is called membership function of set X.

A generalized fuzzy number A is said to be a generalized trapezoidal fuzzy number denoted by (a, b, c, d; w) if its membership is given by 


$$
\mu_{A}(x)= \begin{cases}\frac{w(X-a)}{b-a}, & a \leq X \leq b \\ w \quad, & b \leq X \leq c \\ \frac{w(d-X)}{d-c}, & c \leq X \leq d \\ 0 & \text { elesewhere }\end{cases}
$$

A fuzzy number A is said to be a trapezoidal fuzzy number denoted by $\left(a_{1}, a_{2}, a_{3}, a_{4}\right.$; w) if its membership is given by

$$
\mu_{A}(x)= \begin{cases}\frac{\left(X-a_{1}\right)}{a_{2}-a_{1}}, & a_{1} \leq X \leq a_{2} \\ 1, & a_{2} \leq X \leq a_{3} \\ \frac{\left(a_{4}-X\right)}{a_{4}-a_{3}}, & a_{3} \leq X \leq a_{4} \\ 0 & \text { elesewhere }\end{cases}
$$

The parametric form of a fuzzy number A can be written in terms of ordered pair of functions $\left(a_{\min }(\alpha)\right.$ and $\left.\mathrm{a}_{\max }(\alpha)\right), 0 \leq \alpha \leq$., where $\mathrm{a}_{\min }(\alpha)$ and $\mathrm{a}_{\max }(\alpha)$ are bounded left non decreasing and bounded right non increasing functions over [0,1].In our case , the parametric form of a trapezoidal fuzzy number $B=$ $\left(b^{1}, b^{2}, b^{3}, b^{4}\right)$ can be written as

$\mathrm{B}=\left(\alpha\left(b^{2}-b^{1}\right)+b^{1}, b^{4}-\alpha\left(b^{4}-b^{3}\right)\right)$

The system (1) can be written in parametric form as

Maximize $\mathrm{Z}=\mathrm{c}_{1}\left(\mathrm{x}_{1}^{\mathrm{L}}, \mathrm{x}_{1}^{\mathrm{R}}\right)+\ldots+\mathrm{c}_{\mathrm{n}}\left(\mathrm{x}_{\mathrm{n}}^{\mathrm{L}}, \mathrm{x}_{\mathrm{n}}^{\mathrm{R}}\right)$

Subject to

$a_{h 1}\left(x_{1}{ }^{L}, x_{1}{ }^{R}\right)+\ldots+a_{h n}\left(x_{n}{ }^{L}, x_{n}{ }^{R}\right) \unlhd\left(b_{h}{ }^{L}, b_{h}{ }^{R}\right)$

$\mathrm{X}_{\mathrm{j}}^{\mathrm{L}}, \mathrm{X}_{\mathrm{j}}^{\mathrm{R}} \searrow$. For all $\mathrm{h}=1,2, \ldots, \mathrm{m}$ and $\mathrm{j}=1,2, \ldots, \mathrm{n}$.

Numerical example

A farmer has around 15 hectares farm on which he plants three crops: corn and rice and maize. Each crop has certain requirements for capital(\$) and labor (hrs) as given in table (1) below.

\section{Table 1}

\begin{tabular}{|c|c|c|}
\hline Crop(per acre) & Capital(\$) & Labor(hrs) \\
\hline Rice & 42 & 8 \\
\hline Maize & 24 & 6 \\
\hline oats & 19 & 2 \\
\hline
\end{tabular}


In this example the profit per acre of rice crop is $\$ 30$, per acre of maize crop is $\$ 25$ and per acre of oats crop is $\$ 20$.The total capital and time available for working these crops are about $\$ 400$ and around 45 hours respectively. Now, it is required to determine how many hectares of each crop should be planted in order to maximize the farmer's profit.

Let $\mathrm{x}_{1}$ be the planted area with rice, $\mathrm{x}_{2}$ be the planted area with maize and $\mathrm{x}_{3}$ be the planted area with oats. Each vague data are represented by a trapezoidal fuzzy number as: 15 hectares $=(12,15,17$, $18)$; about $\$ 400=(370,400,430,450)$; around 45 hours $=(40,45,50,55)$.

Now the Fuzzy linear programming problem (Flpp) can be written as

Maximize $Z=30 \mathrm{x}_{1}+25 \mathrm{x}_{2}+20 \mathrm{x}_{3}$

Subject to

$42 \mathrm{x}_{1}+24 \mathrm{x}_{2}+19 \mathrm{x}_{3} \leq(370,400,430,450)$

$8 x_{1}+6 x_{2}+2 x_{3} \leq(40,45,50,55)$

$\mathrm{x}_{1}+\mathrm{x}_{2}+\mathrm{x}_{3} \leq(12,15,17,18)$

$\mathrm{x}_{1}, \mathrm{x}_{2}, \mathrm{x}_{3} \geq 0$

Crisp multi objective linear programming problem of above Flpp can be written as

Maximize $Z^{1}=30 x_{1}{ }^{L}+25 x_{2}{ }^{L}+20 x_{3}{ }^{L}$ and

Maximize $Z^{2}=30 x_{1}{ }^{R}+25 x_{2}{ }^{R}+20 x_{3}{ }^{R}$

Subject to

$0 \leq \alpha \leq 1$

$42 \mathrm{x}_{1}{ }^{\mathrm{L}}+24 \mathrm{x}_{2}{ }^{\mathrm{L}}+19 \mathrm{x}_{3}{ }^{\mathrm{L}} \leq 30 \alpha+370$

$42 \mathrm{x}_{1}{ }^{\mathrm{R}}+24 \mathrm{x}_{2}{ }^{\mathrm{R}}+19 \mathrm{x}_{3}{ }^{\mathrm{R}} \leq 450-20 \alpha$

$8 \mathrm{x}_{1}{ }^{\mathrm{L}}+6 \mathrm{x}_{2}{ }^{\mathrm{L}}+2 \mathrm{x}_{3}{ }^{\mathrm{L}} \leq 5 \alpha+40$

$8 \mathrm{x}_{1}{ }^{\mathrm{R}}+6 \mathrm{x}_{2}{ }^{\mathrm{R}}+2 \mathrm{x}_{3}{ }^{\mathrm{R}} \leq 55-10 \alpha$

$\mathrm{x}_{1}{ }^{\mathrm{L}}+\mathrm{x}_{2}{ }^{\mathrm{L}}+\mathrm{x}_{3}{ }^{\mathrm{L}} \leq 3 \alpha+12$

$\mathrm{x}_{1}{ }^{\mathrm{R}}+\mathrm{x}_{2}{ }^{\mathrm{R}}+\mathrm{x}_{3}{ }^{\mathrm{R}} \leq 18-\alpha$

$\mathrm{x}_{1}^{\mathrm{L}}, \mathrm{x}_{2}^{\mathrm{L}}, \mathrm{x}_{3}^{\mathrm{L}}, \mathrm{x}_{1}^{\mathrm{R}}, \mathrm{x}_{2}^{\mathrm{R}}, \mathrm{x}_{3}^{\mathrm{R}} \geq 0$

The results can be obtained through LINGO 13.0 [9] for different values of $\alpha$ as given in table (2) below.

Table (2) represents the results of crisp linear programming problem.

The optimal solution of the original problem is $\mathrm{x}_{1}=(2,2,2.54,2), \mathrm{x}_{2}=(0,0,0,0), \mathrm{x}_{3}=(9.33,10.91,11.70$, $12.50)$ and the optimal value is $\mathrm{z}=(246.6,278.20,294,310)$.Also it can be seen from table (2) which cropping combination provides us best optimal solution. 
Table 2

\begin{tabular}{|l|l|l|l|l|}
\hline$\alpha$ & 0 & 0.50 & 0.75 & 1 \\
\hline $\mathrm{x}_{1}{ }^{\mathrm{L}}$ & 2 & 2 & 2.54 & 2 \\
\hline $\mathrm{x}_{2}{ }^{\mathrm{L}}$ & 0 & 0 & 0 & 0 \\
\hline $\mathrm{x}_{3}{ }^{\mathrm{L}}$ & 9.33 & 10.91 & 11.70 & 12.50 \\
\hline $\mathrm{x}_{1}{ }^{\mathrm{R}}$ & 3.16 & 2.50 & 2 & 1.83 \\
\hline $\mathrm{x}_{2}{ }^{\mathrm{R}}$ & 0 & 0 & 0 & 0 \\
\hline $\mathrm{x}_{3}{ }^{\mathrm{R}}$ & 14.83 & 15.0 & 15.08 & 15.16 \\
\hline${\text { Maximize } \mathrm{Z}^{1}}^{2}$ & 266.66 & 295.83 & 310.41 & 325.0 \\
\hline Maximize $\mathrm{Z}^{2}$ & 391.66 & 375.00 & 366.66 & 358.33 \\
\hline
\end{tabular}

\section{Conclusion}

This paper has discussed the use of fuzzy linear programming for solving a production planning problem in agriculture. It concludes that how the farmer gets best possible result with the use of limited resources and how FLPP is converted into crisp multi objective linear programming problems. In this paper only trapezoidal membership function is considered. In the future various membership functions will be considered like logistic, s-curve, Z-shaped function, pi function etc.

\section{References}

[1] L. A Zadeh, Inform. Contr., 8 (1965) 338-353.

[2] S. A Orlovsky, Fuzzy Sets and Systems, 3 (1980)311-321.

[3] M. Tamiz, Multi-objective programming and goal programming theories and Applications, Germany : SpringerVerlag, 1996.

[4] H.J. Zimmermann, Fuzzy Set Theory and Its Applications, (2 ${ }^{\text {nd }}$ rev .ed). Boston: Kulwer, 1991.

[5] T.J. Ross, Fuzzy logic with engineering Applications, New York: McGraw-Hill, 1995.

[6] P. Senthilkumar and G. Rajendran, On the solution of Fuzzy linear programming Problem, International journal of computational Cognition, 8(3) (2010)45-47.

[7] L. Campos and J. L. Verdegay, Fuzzy Sets and Systems, 32 (1989)1-11.

[8] H.R. Maleki, M. Tata, M. Mashinchi, Fuzzy Sets and Systems, 9 (2000)21-33.

[9] Lingo 13.0, LINDO Inc. Ltd. 